\title{
EDUKASI KEBUTUHAN DASAR PENDIDIKAN ANAK USIA DINI MELALUI METODE PUMPING PADA IBU PEKERJA
}

\author{
EDUCATION OF EARLY CHILDREN'S BASIC NEEDS THROUGH THE \\ PUMPING METHOD IN WORKER MOTHER
}

\author{
1) Melia Eka Daryati , ${ }^{2)}$ Yulidesni \\ ${ }^{1,2}$ Fakultas Keguruan dan Ilmu Pendidikan, Universitas Bengkulu \\ *melia_eka@unib.ac.id
}

\begin{abstract}
ABSTRAK
Pendidikan anak usia dini dimulai dari usia bayi yang baru lahir melalui rangsangan pemberian ASI, tidak mudah menjadi seorang ibu yang selalu memberikan ASI kepada anaknya dikarenakan status pekerjaan ibu yang berkerja di luar rumah sehingga menitipkan anak ke lembaga penitipan anak. Seorang ibu tetap dapat memberikan ASI dengan menggunakan metode pumping. Tujuan terlaksananya pengabdian masyarakat untuk memberikan edukasi kebutuhan dasar PAUD melalui metode pumping pada ibu yang bekerja di luar rumah sebagai alternatif pilihan yang tepat untuk memberikan ASI pada Taman Penitipan Anak PAUD Al-Ikhlas yang berjumlah 14 orang. Metode pengabdian menggunakan model technical assistance berupa edukasi penyuluhan dan pendampingan. Hasil kegiatan ini menunjukkan 1) Peserta pengabdian telah memiliki pengetahuan metode pumping sebagai alternatif dalam memberikan ASI bagi ibu yang bekerja diluar, 2) Peserta pengabdian telah memahami penerapan metode pumping baik menggunakan pumping manual maupun menggunakan pumping elektrik, dan 3) Peserta pengabdian memahami cara penyimpanan ASI perah selama ibu berkerja. Perlu edukasi agar seorang ibu tetap memberikan ASI kepada anak walaupun status pekerjaan di luar rumah sehingga kebutuhan ASI tetap bisa terpenuhi untuk anak melalui penggunaan metode pumping.
\end{abstract}

Kata Kunci : ibu pekerja , kebutuhan dasar PAUD, metode pumping

\section{ABSTRACT}

Early childhood education starts from the age of a newborn through the stimulation of breastfeeding, it is not easy to become a mother who always gives breast milk to her child because of the mother's work status outside the home so that she entrusts the child to a child care institution. A mother can still breastfeed using the pumping method. The aim of implementing community service is to provide education on the basic needs of early childhood education through the pumping method for mothers who work outside the home as the right alternative to breastfeeding at the Al-Ikhlas PAUD Child Care Park, which amounts to 14 people. The service method uses a technical assistance model in the form of counseling and mentoring education. The results of this activity show 1) Community service participants have knowledge of the pumping method as an alternative in providing breast milk for mothers who work outside, 2) Community service participants have understood the application of the pumping method both using manual pumping and using electric pumping, and 3) Community service participants understand how to store Breastmilk while working. Education is needed so that a mother continues to provide breast milk to a child even though the status of employment is outside the home so that breastfeeding needs can still be fulfilled for the child through the use of the pumping method.

Keywords: the workers, the basic needs of early childhood, a method of pumping

Diterima :21-05-2021 Disetujui : 01-06-2021 Dipublikasikan: 30-06-2021 


\section{PENDAHULUAN}

Taman Penitipan Anak Pendidikan Anak Usia Dini (PAUD) menjadi salah satu selusi yang dipilih ibu yang bersatus berkerja di luar, mulai usia 3 bulan anak mulai dititipkan di Taman Penitipan Anak , biasanya ibu mulai menitipkan anak dari pukul 7.30 WIB sampai waktu ibu selesai berkerja. Status ibu sebagai pekerja menjadi pilihan ibu menitipkan anak di Taman Penitipan Anak PAUD Al-Ikhlas di daerah Kelurahan Kandang Limun, Kecematan Muara Bangkahulu Kota Bengakulu yang saat sekarang terdapat 12 bayi dan 9 anak dan balita, tidak dipungkiri bayi yang di titipkan ditempatkan Taman Penitipan Anak anak diberikan susu formula sebagai pengganti Air Susu Ibu (ASI).

Ibu pekerja memiliki masalah utama dalam memberikan makanan pada bayinya, keterbatasan waktu pada saat berkerja menyebabkan ibu tidak dapat memberikan ASI secara langsung, seringkali ditemukan ibu yang menitipkan anak memberikan Pengganti Air Susu Ibu (PASI) berupa susu formula kepada bayinya. Pemberian PASI kepada bayi 0-6 bulan sangat tidak di anjurkan dalam dasar PAUD, kerena ASI ekslusif menjadi dasar awal dalam PAUD, artinya perlu metode agar ASI Ekslusif dapat terpenuhi, seperti metode exclusive pumping (e-pumping) sebagai rujukan untuk ibu pekerja.

Metode pumping sering disebut metode pompa ASI, salah satu metode yang paling efektif dan efesien meningkat kepercayaan ibu memberi ASI ekslusif, karena metode ini bayi akan tetap memperoleh ASI pada saat ibunya berkerja. Metode pumping dapat dilakukan dengan menggunakan jari tangan dan alat pompa, ibu yang ingin memulai pompa ASI sering mengalami kendala berupa terasa perih dan sakit pada saat memompa ASI sehingga ibu memutuskan untuk tidak kembali memompa ASI, perlunya edukasi kepada ibu dalam memahami cara memompa ASI dan pemilihan alat pompa ASI yang tepat. Metode pumping yang baik akan meningkatkan produksi ASI dan memberikan rasa nyaman pada ibu, sehingga ibu dapat tetap memberikan ASI secara ekslusif pada bayinya, hal ini sesuai dengan penelitian Aggreni (2018, p. 7) yang menyatakan terdapat pengaruh penggunaan metode pompa ASI terhadap pemberian ASI ekslusif pada ibu perkerja dan penelitian lain menyatakan penggunanan pompa elektrik mendukung keberhasilan ASI ekslusif (Nur, 2019, p. 4).

Pemberian ASI Ekslusif diberi dari 0-6 bulan yang akan berdampak luas terhadap status gizi dan kesehatan secara optimal Kemengkes RI (2003, p. 15). Penididikan Anak Usia Dini (PAUD) harus dimulai dari bayi yang baru lahir, artinya dasar utama dalam edukasi anak usia dini dimulai dari bayi 0 bulan (Depdiknas., 2003, p. 9). Edukasi pertama yang di terapkan adalah bayi yang baru lahir diberikan ASI sampai bayi usia 6 bulan. ASI menjadi makanan yang terbaik untuk bayi dan pada saat sekarang belum ada jenis makanan yang dapat menandingi ASI, namun secara kenyataan kurangnya pemahaman menganai ASI membuat ibu beralih memberi susu formula yang menganggap susu formula lebih mengenyangkan dibandingkanan ASI dan dapat membuat 
anak lebih lebih cerdas. Berdasarkan penelitian Astuti (2011, p. 4) menyatakan $87 \%$ ibu pekerja memberi susu formula menganggap ASI tidak megeyangkan.

Kurangnya pemahaman dan pengetahuan mengenai ASI menyebabkan susu formula menjadi makanan idola yang diberikan ke bayi, kurangnya edukasi mengenai ASI membuat ibu memilki persepsi bahwa ASI tidak mencukupi. Produksi ASI sangat tergantung dari isapan bayi yang merangsang oksitosin dan prolactin, selain melalui isapan dapat dilakukan melalui metode pumping yang membatu pengosongan alveoli memmae yang membabkan naiknya sekresi porlaktin, hingga meningatkan produksi ASI ibu (Noayelelinda, 2012, p. 10).

Ibu Pekerja perlu diberi edukasi mengenai ASI, sehingga mereka memahami betapa pentingya ASI untuk bayi, terutama usia 0-6 bulan yang harus diberi secara ekslusif. Edukasi ASI salah satu upaya peningkatan mutu kualitas anak usia dini, hal ini dapat dilakukan dengan cara memberi informasi mengenai manfaat ASI, serta memberi selusi kepada ibu pekerja yang menitipkan anaknya ke Taman Penitipan Anak bagaimana tetap memberi ASI dengan metode pumping sebagai pilihan yang tepat, sehingga bayi memperoleh ASI secara ekslusif.

\section{METODE}

Metode yang digunakan dalam kegiatan ini adalah model technical assistance dalam bentuk edukasi berupa peyuluhan dan pendampingan dengan memberikan edukasi dan pendampingan pada ibu yang menitipkan anaknya tentang konsep dasar anak usia dini, melalui kebutuhan dasar berupa pentingya ASI ekslusif untuk bayi dan penggunaan metode pumping sebagai pilihan yang tepat untuk ibu yang berkerja diluar sehingga harus menitipkan anaknya ke Taman Penitipan Anak Al-Ikhlas. Metode kegiatan yang dilakukan dalam pengabdian masyarakat ini menggunakan empat tahapan diantaranya sebagai berikut:

\section{Tahap I (Studi Pendahuluan)}

Pada tahap ini kegiatan yang dilakukan oleh tim pengabdian di antaranya adalah:

a. Melakukan studi pustaka untuk mengkaji permasalahan yang akan dipecahkan melalui kegiatan pengabdian.

b. Melakukan pengumpulan data berupa wawancara terbuka mengenai penitipan anak.

c. Persiapan narasumber luar dalam kegiatan penyuluhan ASI Ekslusif

d. Persiapan materi penyuluhan. Untuk bahan pelaksanaan pelatihan ini dilakukan dengan menggunakan modul yang sudah terstandar dari Kementrian Kesehatan.

e. Persiapan alat-alat yang digunakan untuk pendampingan metode Pumping, sebagai inti kegiatan pelaksanaan Pengabdian Masyarakat.

2. Tahap II (Pelaksanaan)

Pada tahap ini dilakukan rangkaian kegiatan pelatihan yang terdiri dari:

a. Penyuluhan ASI Ekslusif, pada tahap ini rangkain informasi yang berhubungan pengetahuan mengenai ASI Ekslusif yang diberikan kepada ibu pekerja yang menitipkan anaknya, ASI yang menjadi salah satu dasar pendidikan anak usia dini. 
Alat dan bahan yang dibutuhkan dalam kegiatan ini dapat dilihat pada Tabel berikut:

b. Kegiatan penyuluhan dibantu oleh narasumber yang berbasis berbasis kesehatan yang sangat memahami mengenai ASI, diharapkan dengan dibantu peran tenaga kesehatan yang berkempoten dibidangkan, ibu-ibu pekerja merasa yakin informasi yang diterima dalam kegiatan penyuluhan menjadi informasi penting diterapkan dan berkeinginan memberi ASI melalui metode Pumping mejadi selusi tepat untuk ibu.

\section{Tahap III (Pendampingan)}

Pada tahap ini kegiatan yang dilakukan adalah:

a. Pendampingan tahap berikutnya setelah penyuluhan, dengan adanya penyuluhan sebagai informasi mengenai ASI, maka ibu pekerja diberi selusi untuk tetap memberi dengan metode pumping.

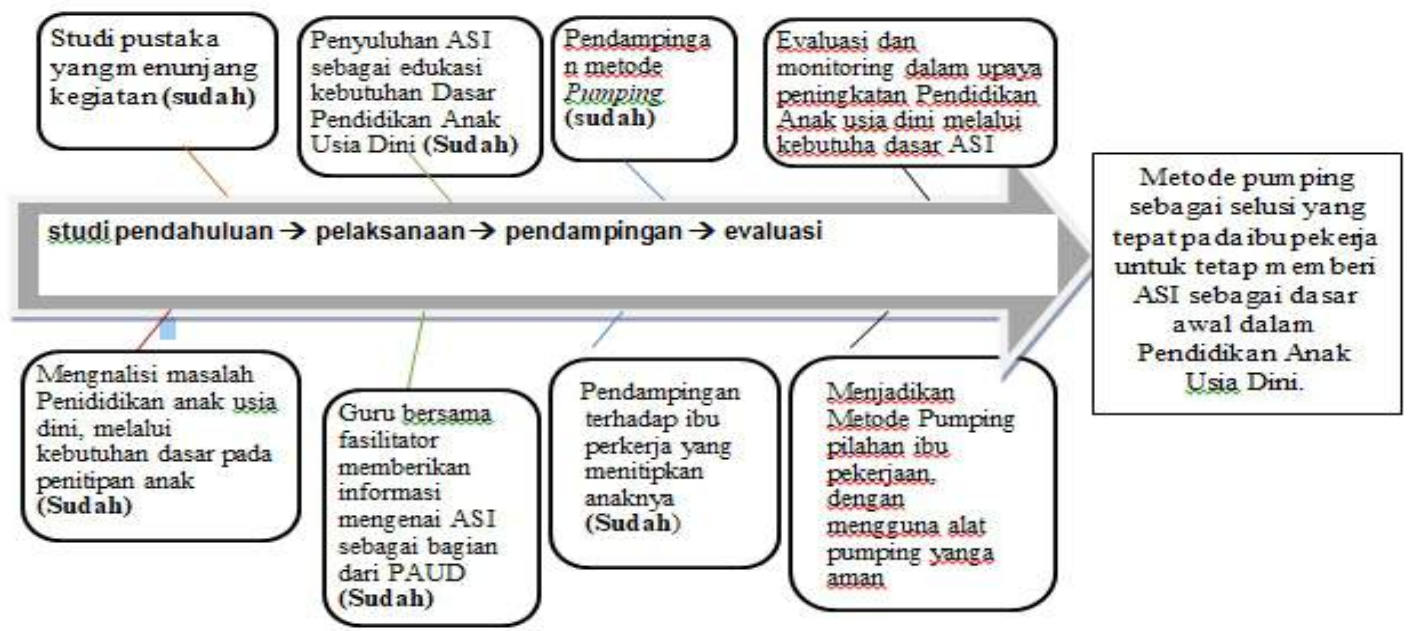

Gambar1. Prosedur pelatihan yang akan dilakukan

Peserta kegiatan pengabdian anaknya pada PAUD Al-Ikhlas Kota adalah para orang tua yang menitipkan Bengkulu sebanyak 14 orang. Kegiatan b. Pendampingan pada ibu pekerja mengenai metode pumping sangat perlu diberikan, agar ibu dapat mengenal pumping dengan beberapa cara, baik cara dengan manual maupun menggunakan alat. Penggunaan alat sangat perlu diberi dampingan, sehingga ibu tidak salah memilih alat pumping dan cara penggunaannya. Bahan atau alat yang digunakan dalam pendampingan:

\section{Tahap IV (Evaluasi)}

Pada tahap ini kegiatan yang dilakukan adalah:

a. Monitoring dan evaluasi yang diberikan untuk melihat bagaimana keinginan ibu untuk ingin beralih ke metode pumping sebagai selusi terbaik untuk tetap memberi ASI.

b. Melakukan upaya tindak lanjut dari hasil evaluasi.

Skema pelaksanaan metode kegiatan secara rinci dapat dilihat pada Gambar 1 di bawah ini: 
dilaksanakan diruangan samping sekolah PAUD Al-Ikhlas yang Jalan. Pondok Bulat, No. 25, RT 10, RW 02, Kelurahan Kandang Limun, Kecamatan Muara Bangkahulu, Kota Bengkulu.

\section{HASIL DAN PEMBAHASAN}

Pelaksanaan kegiatan pengabdian ini melibatkan Fakultas Keguruan dan Ilmu Pendidikan Universitas Bengkulu sebagai lembaga penyelenggara pembinaan dan sekolah PAUD Al-Ikhlas Kota Bengkulu sebagai tempat kegiatan pengabdian. Fakultas Keguruan dan Ilmu Pendidikan Universitas Bengkulu dan sekolah PAUD Al-Ikhlas Kota Bengkulu yang menjadi mitra dalam kegiatan ini. Fakultas Keguruan dan Ilmu Pendidikan Universitas Bengkulu memiliki potensi berupa berupa fasilitas pembelajaran dan

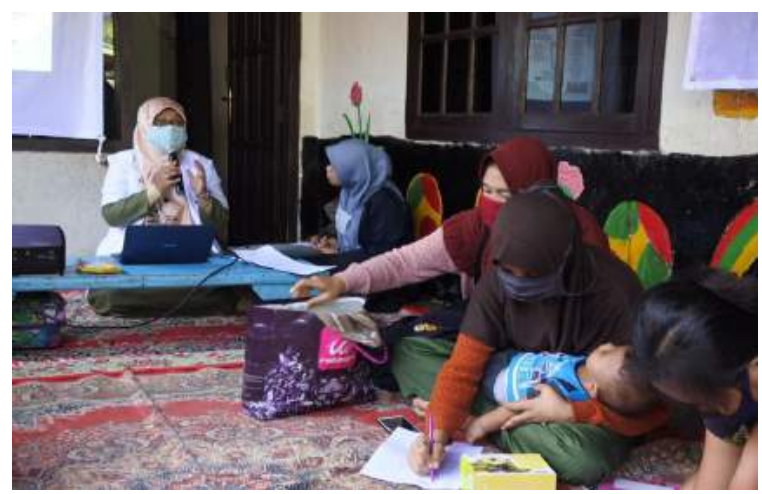

Gambar 2. Penyampaian Materi Pengabdian Narasumber Dokter

Institusi Puskesmas Kelurahan Kandang Limun, tentuya perlu peran serta petugas kesehatan dalam meningkatkan kesehatan masyarakat, salah satunya peningatan kesehatan anak usia dini. ASI Ekslusif merupakan salah satu program yang dijalan puskesmas
Sumber Daya Manusia (SDM) yang mendukung pelaksanaan kegiatan pengabdian ini sekolah PAUD Al-Ikhlas Kota Bengkulu memiliki layanan penitipan anak, kelompok bermain, dan taman kanak-kanak yang melayani anak usia dini. Para guru yang ada di PAUD Al-Ikhlas Kota Bengkulu berjumlah 5 orang dengan latar belakang pendidikan yang berbeda-beda. Para guru PAUD AlIkhlas Kota Bengkulu yang menjadi peserta dalam kegiatan ini memiliki motivasi yang tinggi dalam memberikan pelayanan pendidikan kepada anak usia dini, selain itu PAUD Al-Ikhlas Kota Bengkulu memiliki fasilitas melayani penitipan anak yang dimulai dari 3 bulan keatas. Kegiatan ini akan dapat menjadi penilaian tambahan bagi guru untuk menjadi salah satu program PAUD unggulan dalam peningkatan mutu Pendidikan PAUD Al-Ikhlas.

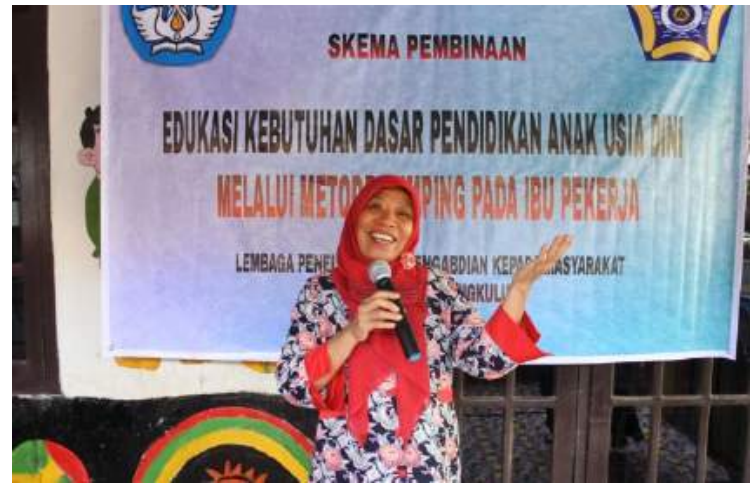

Gambar 3. Penyampaian Materi Pengabdian Narasumber Praktisi PAUD

dalam peningkatan kesehatan anak usia dini secara optimal. Kegiatan pengabdian yang dilakukan akan membantu program puskesmas dalam upaya pemberian ASI Ekslusif pada bayi, sehingga kecapaian masyarakat dalam pemberian ASI Ekslusif dapat tercapai. 


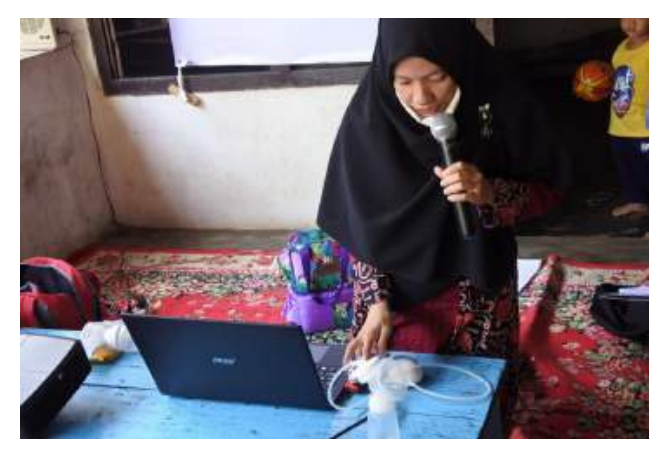

Gambar 4. Memberikan Pendampingan Alat Pumping

Evaluasi kegiatan dilakukan menggunakan lembar angket yang berisi kuisioner tentang kegiatan edukasi kebutuhan dasar pendidikan anak usia dini melalui metode pumping pada ibu pekerja. Rancangan evaluasi akan difokuskan untuk mengukur ketertarikan ibu mengenai metode pumping atau yang sejenisnya bila meninggalkan anak yang dikarenakan ibu bekerja. Evaluasi akan dilakukan dengan menggunakan instrumen angket yang berisi butir-butir pernyataan dengan menceklist jawaban $(\sqrt{ })$ untuk jawaban iya dan (x) untuk jawaban tidak terhadap kriteria angket yang ditanyakan.

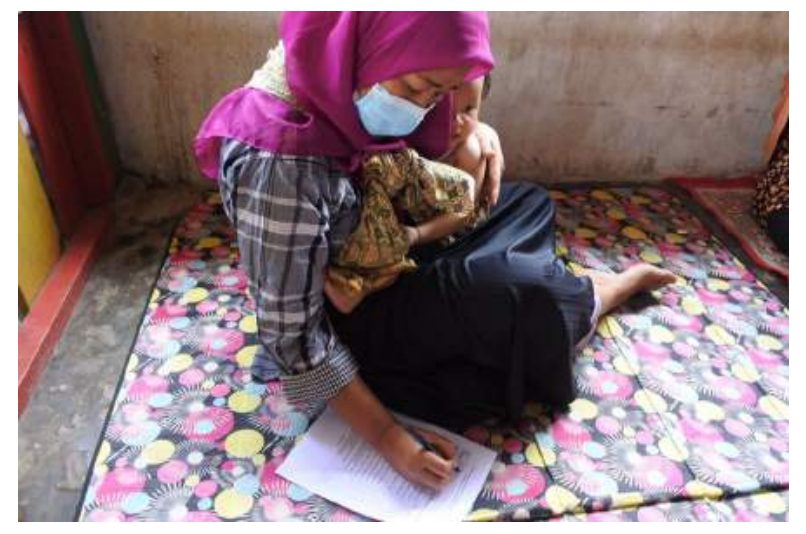

Gambar 5. Pengisian Angket Pengabdian

Lembar angket kegiatan digunakan sebagai acuan pengamatan dalam mengetahui pemahaman dan kebiasaan yang dilakukan oleh peserta pada saat pelaksanaan pengabdian berlangsung. Hasil dari lembar angket ini kemudian dianalisis dan dideskripsikan sesuai data angket yang diperoleh. 

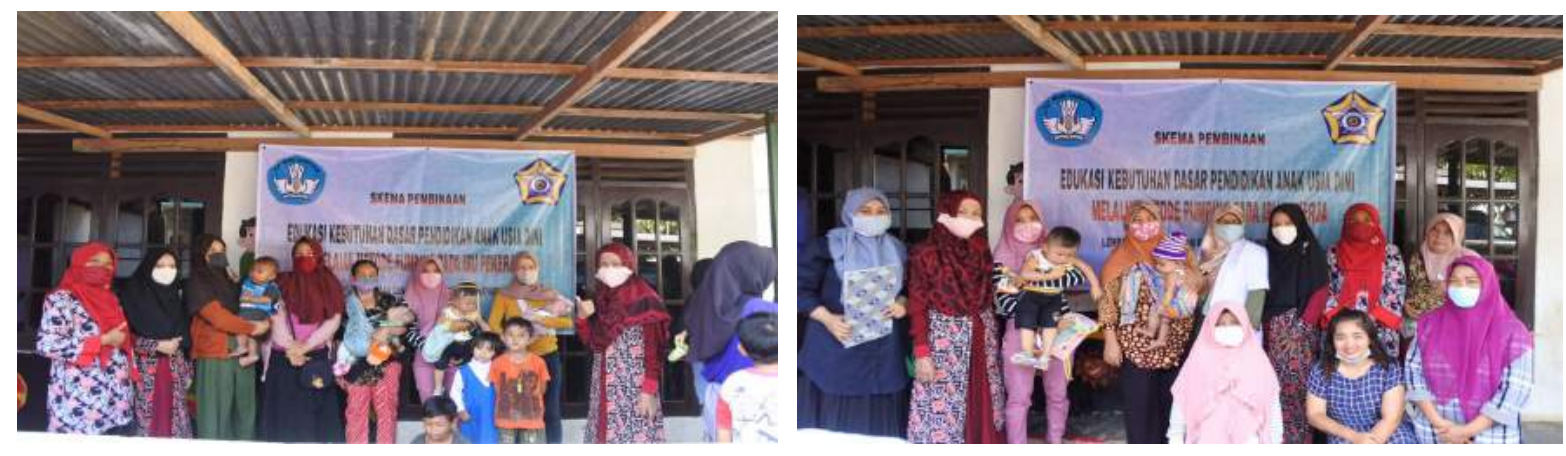

Gambar 6. Foto Bersama Dengan Peserta Pengabdian

Berdasarkan hasil evaluasi kegiatan yang dilakukan terhadap peserta kegiatan pengabdian edukasi kebutuhan dasar pendidikan anak usia dini melalui metode pumping pada ibu pekerja, maka diperoleh data evaluasi berupa pemahaman dan pembiasaan para ibu-ibu secara kuantitatif dan kualitatif. Data hasil evaluasi kuantitatif berupa persentase pemahaman dan pembiasaan para ibu pekerja menggunakan metode pumping atau memera sejenisnya dalam menitipkan anak ketika melakukan aktivitas diluar sehingga anak harus mengkonsumsi asi atau susu formula. Sedangkan data hasil evaluasi kualitatif berupa deskripsi analisis kebutuhan dasar anak usia dini melalui metode pumping pada ibu pekerja. Data persentase edukasi kebutuhan dasar pendidikan anak usia dini melalui metode pumping pada ibu pekerja dapat dilihat pada Tabel 1 .

Tabel 1. Kisi-Kisi Rancangan Evaluasi

\begin{tabular}{|c|c|c|c|}
\hline No & Kriteria & $\begin{array}{l}\text { Persentase } \\
(\%)\end{array}$ & Kriteria \\
\hline 1 & $\begin{array}{l}\text { Apakah ibu mengetahui bahwa pendidikan anak usia dini dimulai } \\
\text { dari bayi baru lahir? }\end{array}$ & 21.4 & Kurang \\
\hline 2 & $\begin{array}{l}\text { Apakah ibu mengetahui air susu ibu merupakan salah satu dasar } \\
\text { pendidikan anak usia dini? }\end{array}$ & 14.2 & Baik \\
\hline 3 & $\begin{array}{l}\text { Apakah ibu memahami bahwa ASI sangat penting untuk } \\
\text { pekembangan anak? }\end{array}$ & 92.8 & Baik \\
\hline 4 & $\begin{array}{l}\text { Apakah ibu berusaha untuk memberikan asi kepada anak selama ibu } \\
\text { bekerja? }\end{array}$ & 42.8 & Baik \\
\hline 5 & Apakah ibu perna mengdengar asi eksklusif? & 100 & Baik \\
\hline 6 & $\begin{array}{l}\text { Apakah ibu selama bekerja memberi selain asi kepada bayi yang } \\
\text { dititipkan di penitipan anak? }\end{array}$ & 100 & Kurang \\
\hline 7 & Apakah ibu pernah mencoba untuk memompa asi? & 35,7 & Baik \\
\hline 8 & Apakah ibu memompa asi secara manual? & 42,9 & Baik \\
\hline 9 & $\begin{array}{l}\text { Apakah ibu memompa asi dengan menggunakan alat pompa baik } \\
\text { elektrik maupun manual? }\end{array}$ & 28,6 & Baik \\
\hline 10 & $\begin{array}{l}\text { Apakah ibu memahami cara memompa asi secara manual ataupun } \\
\text { menggunakan alat pompa asi? }\end{array}$ & 28,6 & Baik \\
\hline 11 & $\begin{array}{l}\text { Apakah ibu memahami cara menyimpan asi yang baik pada kulkas } \\
\text { satu pintu maupun dua pintu? }\end{array}$ & 57,1 & Baik \\
\hline 12 & $\begin{array}{l}\text { Apakah ibu mengetahui cara memanaskan asi yang baik setelah di } \\
\text { bekukan? }\end{array}$ & 64,3 & Baik \\
\hline 13 & $\begin{array}{l}\text { Apakah ibu mengetahui berapa lama waktu yang baik dalam } \\
\text { mengkonsumsi asi setelah dipanaskan? }\end{array}$ & 42,9 & Kurang \\
\hline
\end{tabular}




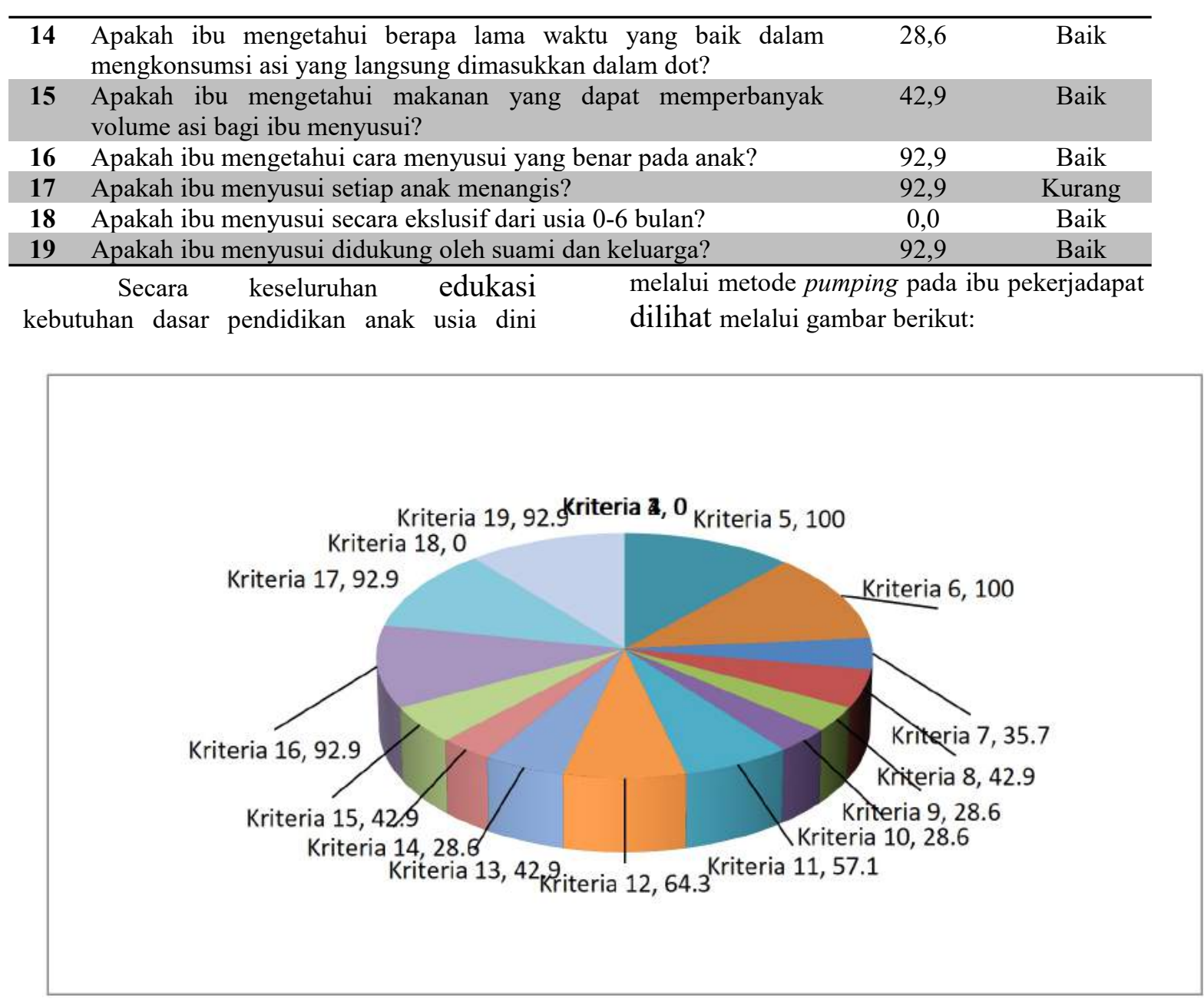

Gambar 7. Persentase Kriteria

\section{SIMPULAN}

Berdasarkan hasil dan mengenai metode pumping kepada ibu pembahasan dapat disimpulkan bahwa edukasi ASI ekslusif memberi informasi pentingnya ASI ekslusif untuk bayi, ibu pekerja yang mengetahui ASI ekslusif $100 \%$, namun belum bisa memberi ASI Ekslusif pada bayinya. Edukasi pekerja menjadi selusi yang tepat untuk tetap memberikan ASI kepada bayi saat ibu berkerja. Keinginan ibu pekerja memberi asi eklusif semakin tinggi setelah mengetahui manfaat ASI begitu besar pada bayi

\section{DAFTAR PUSTAKA}

Anggreni, S. (2018). Pengaruh Penggunaan Metode Pompa ASI
(MPA) terhadap Pemberian ASI Ekslusif pada Ibu Pekerjaandi Wilayah Tologomas Kota Malang. Jurnal Nursing News, 3(1), 1-11. 
Astuti, W. (2011). Ilmu Gizi. Puspa Swara.

Depdiknas. (2003). Undang-undang RI No.20 tahun 2003.tentang sistem pendidikan nasional. Jakarta. http://www.inherentdikti.net/files/sisdiknas.pdf

Noayelelinda. (2012). Telaah Literatur Pemberian ASI dan Ibu Berkerja. Jurnal Ners Indonesia, 2(2), 17714.

Nur, K. F. S. D. (2019). Penggunaan Pompa ASI Elektrik oleh Ibu Pekerja. Jurnal Smart Kebidanan, 6(2), 87-92.

RI, K. (2003). Ibu Bekerja Tetap Berikan Air Susu Ibu (ASI). Direktorat Jenderal Bina Kesehatan Masyarakat. 